\title{
PAPER
}

Check for updates

Cite this: J. Mater. Chem. A, 2018, 6 , 13943

Received 21st April 2018

Accepted 22nd June 2018

DOI: $10.1039 / \mathrm{c} 8 \mathrm{ta0} 03667 \mathrm{e}$

rsc.li/materials-a

\section{Metastable and nanosize cation-disordered rocksalt-type oxides: revisit of stoichiometric $\mathrm{LiMnO}_{2}$ and $\mathrm{NaMnO}_{2} \uparrow$}

\begin{abstract}
Takahito Sato, ${ }^{a}$ Kei Sato, ${ }^{a}$ Wenwen Zhao, ${ }^{\text {ab }}$ Yoshio Kajiya ${ }^{c}$ and Naoaki Yabuuchi (D) *abd
Stoichiometric $\mathrm{LiMnO}_{2}$ and $\mathrm{NaMnO}_{2}$ with a cation-disordered rocksalt-type structure as metastable polymorphs were successfully prepared by mechanical milling. Although cation-disordered rocksalt phases with a stoichiometric composition ( $\mathrm{Li}: \mathrm{Mn}$ molar ratio $=1: 1$ ) are expected to be electrochemically less active, both samples show superior performance as electrode materials when compared with thermodynamically stable layered phases in Li/Na cells. Both metastable samples deliver large reversible capacities, which correspond to $>80 \%$ of their theoretical capacities, with relatively small polarization on the basis of reversible $\mathrm{Mn}^{3+} / \mathrm{Mn}^{4+}$ redox. Moreover, for rocksalt $\mathrm{LiMnO}_{2}$, the phase transition into a spinel phase is effectively suppressed compared with a thermodynamically stable phase. The electrode reversibility of $\mathrm{NaMnO}_{2}$ is also drastically improved by the use of the metastable phase with good capacity retention. Metastable phases with unique nanostructures open a new path for the design of advanced electrode materials with high energy density, and thus a broad impact is anticipated for rechargeable Li/Na battery applications.
\end{abstract}

\section{Introduction}

The research progress in rechargeable Li batteries in the past two decades has contributed to development of innovative technology in modern society, and our daily life has been drastically changed thanks to convenient portable electronic devices. Moreover, the market of electric vehicles equipped with rechargeable Li batteries and electric motors is rapidly growing, and this movement in the automotive industry potentially leads to the sustainable energy development on the basis of renewable energy resources in the future. Nevertheless, the growth rate of the electric vehicle market is dampened by high battery cost and the limited energy density in current Li batteries. The greatest barrier to further improve the energy density of current Li-ion batteries is found in the limited energy density for positive electrode materials. Innovative positive electrode materials are therefore indispensable. In addition, the research on largescale energy storage systems combined with renewable energy

${ }^{a}$ Department of Applied Chemistry, Tokyo Denki University, 5 Asahicho Senju, Adachi, Tokyo 120-8551, Japan

${ }^{b}$ Elements Strategy Initiative for Catalysts and Batteries, Kyoto University, f1-30 GoryoOhara, Nishikyo-ku, Kyoto 615-8245, Japan

'Technology Department, Electronic Materials Group, JX Nippon Mining \& Metals Corporation, 1-2, Otemachi 1-Chome, Chiyoda-ku, Tokyo 100-8164, Japan

${ }^{d}$ Department of Chemistry and Life Science, Yokohama National University, 79-5 Tokiwadai, Hodogaya-ku, Yokohama, Kanagawa 240-8501, Japan. E-mail: yabuuchi-naoaki-pw@ynu.ac.jp

$\dagger$ Electronic supplementary information (ESI) available. See DOI: 10.1039/c8ta03667e resources, including solar cells and wind turbines, is an urgent topic. ${ }^{1}$ Rechargeable $\mathrm{Na}$ batteries are a promising candidate for this purpose, but the limited energy density of the electrode materials hinders their use for practical applications. Materials innovation for $\mathrm{Li} / \mathrm{Na}$ battery applications is indispensable to realize the green energy society in the future.

For battery applications, elemental abundance, which directly correlates to the cost of batteries, is an essential parameter, and manganese is an attractive candidate based on this perspective. ${ }^{2}$ Among Li-containing Mn-based oxides, spinel-type $\operatorname{LiMn}_{2} \mathrm{O}_{4}$ and its derivatives have been the most widely studied as positive electrode materials for Li batteries, and have been widely used for commercial applications. ${ }^{3-6}$ Stoichiometric $\mathrm{LiMnO}_{2}$, whose thermodynamically stable phase crystallizes into a zigzag-type layered structure with an orthorhombic symmetry, ${ }^{7}$ is less attractive as an electrode material because its unfavorable phase transition during lithiation/ delithiation cannot be suppressed in this system. Zigzag-type layered $\mathrm{LiMnO}_{2}$ easily translates into the spine-like phase, which is probably associated with a mobile character of trivalent Mn ions. ${ }^{8}$ The nanosize domains of the spinel phase are formed on electrochemical cycling, ${ }^{9}$ and these domains are further grown on extended cycling. In contrast to $\mathrm{LiMnO}_{2}$, for the $\mathrm{Na}$ counterpart, layered $\mathrm{NaMnO}_{2}\left(\alpha-\mathrm{NaMnO}_{2}\right)$, which is isostructural with $\alpha-\mathrm{NaFeO}_{2}$, is easily prepared by conventional solid-state calcination and can be used as positive electrode materials for $\mathrm{Na}$ battery applications. $\mathrm{NaMnO}_{2}$ delivers a large reversible capacity of $\sim 200 \mathrm{~mA} \mathrm{~h} \mathrm{~g}{ }^{-1}$, which corresponds to approximately $80 \%$ of the theoretical capacity in Na cells, but 
this capacity retention is not acceptable for the application of $\mathrm{NaMnO}_{2}$ as electrode material for batteries. ${ }^{\mathbf{1 0}}$ Additionally, $\alpha$ $\mathrm{NaMnO}_{2}$ was also used as a precursor to synthesize $\mathrm{LiMnO}_{2}$, which is isostructural with $\alpha-\mathrm{NaFeO}_{2}$, by $\mathrm{Na} / \mathrm{Li}$ ion-exchange. ${ }^{\mathbf{1 1 , 1 2}}$ $\mathrm{LiMnO}_{2}$ with $\alpha-\mathrm{NaFeO}_{2}$-type structure was directly prepared by a hydrothermal method using a highly concentrated $\mathrm{KOH}$ aqueous solution. ${ }^{13}$ However, conventional layered $\mathrm{LiMnO}_{2}$ also shows the similar phase transition process to zigzag-type layered $\mathrm{LiMnO}_{2} \cdot{ }^{\mathbf{9 , 1 4}}$

In the past few years, many "Li-excess" positive electrode materials with disordered rocksalt-type oxides have been proposed as new high-capacity positive electrode materials. ${ }^{15-18}$ Percolation theory is generally used to explain facile lithium migration in these materials with disordered structure, and percolation probability increases with an increase in the Liexcess level..$^{15,18-20}$ Herein, we report a new insight to design positive electrode materials with disordered structures. It was found that Li-excess is not a necessary condition to extract $\mathrm{Li} / \mathrm{Na}$ ions from the disordered structure, and excellent electrode performance is achieved simply by shortening the migration length in particles. In this study, non Li-excess and stoichiometric $\mathrm{LiMnO}_{2}$ and $\mathrm{NaMnO}_{2}$ were used to develop positive electrode materials for $\mathrm{Li} / \mathrm{Na}$ batteries. Nanosize $\mathrm{LiMnO}_{2}$ and $\mathrm{NaMnO}_{2}$ with disordered structure were successfully synthesized by mechanical milling, which is a unique method to synthesize metastable cation-/anion-disordered phases. ${ }^{21-25}$ The as-prepared nanomaterials show significantly improved electrode performance compared with the samples before mechanical milling. Based on these results, the effectiveness of the synthesis of nanosize and metastable Mn-based electrode materials for Li/Na battery applications is described, and the impact of crystal structures and particle sizes on the electrochemical properties is discussed.

\section{Experimental}

Synthesis of metastable and nanosize $\mathrm{LiMnO}_{2}$ and $\mathrm{NaMnO}_{2}$

Cation-disordered rocksalt-type $\mathrm{LiMnO}_{2}$ and $\mathrm{NaMnO}_{2}$ was prepared by mechanical milling using a planetary ball mill (PULVERISETTE 7; FRITSCH). Orthorhombic zigzag-layered $\mathrm{LiMnO}_{2}$ and monoclinic layered $\mathrm{NaMnO}_{2}$, which are thermodynamically stable phases, were used as precursors for mechanical milling. Initially, $1.5 \mathrm{~g}$ of $\mathrm{LiMnO}_{2}$ or $\mathrm{NaMnO}_{2}$ was mixed using a zirconia pot ( $45 \mathrm{~mL})$ and zirconia balls $(15.5 \mathrm{~g})$ at $600 \mathrm{rpm}$ for $12 \mathrm{~h}$. After the milling for $12 \mathrm{~h}$, the mixture was taken out from the container and mixed with a mortar and pestle to ensure sample uniformity during the milling. The mixture was again milled using the zirconia pot and balls at $600 \mathrm{rpm}$ for $12 \mathrm{~h}$. This process was repeated three times and finally, the mixture was milled for $36 \mathrm{~h}$ in total. $\mathrm{LiMnO}_{2}$ was prepared from $\mathrm{Li}_{2} \mathrm{CO}_{3}\left(98.5 \%\right.$, Kanto Kagaku) and $\mathrm{Mn}_{2} \mathrm{O}_{3}$ at $900{ }^{\circ} \mathrm{C}$ for $12 \mathrm{~h}$ in $\mathrm{Ar}$ atmosphere. $\mathrm{NaMnO}_{2}$ was synthesized from $\mathrm{Na}_{2} \mathrm{CO}_{3}$ (99.5\%; Wako Pure Chemical Industries, Ltd.) and $\mathrm{Mn}_{2} \mathrm{O}_{3}$ at $800{ }^{\circ} \mathrm{C}$ for $8 \mathrm{~h}$ in Ar atmosphere. $\mathrm{Mn}_{2} \mathrm{O}_{3}$ was obtained by heating $\mathrm{MnCO}_{3}$ (Kishida Chemical Co., Ltd.) at $850{ }^{\circ} \mathrm{C}$ for $12 \mathrm{~h}$ in air. After the preparation, the samples were stored in an Ar-filled glove box. The sample handling before and after the mechanical milling was also carried out in the Ar-filled glove box without exposure to moist air.

\section{Electrochemical measurement}

The electrode performance of the samples was examined for the carbon composite samples prepared by ball milling. Mechanically milled $\mathrm{LiMnO}_{2}$ or $\mathrm{NaMnO}_{2}$ was mixed with acetylene black (HS-100; Denka Co., Ltd., LiMnO $\left(\mathrm{NaMnO}_{2}\right): \mathrm{AB}=$ $90: 10 \mathrm{wt} \%$ ) by using the planetary ball mill at $300 \mathrm{rpm}$ for $12 \mathrm{~h}$ with the zirconia container and balls. Composite positive electrodes, comprising $76.5 \mathrm{wt} \% \mathrm{LiMnO}_{2}$ (or $\mathrm{NaMnO}_{2}$ ), $13.5 \mathrm{wt} \%$ acetylene black, and $10 \mathrm{wt} \%$ polyvinylidene fluoride (KF 1100; Kureha Co. Ltd.), were pasted on aluminum foil as a current collector. The electrodes were dried at $80{ }^{\circ} \mathrm{C}$ for $2 \mathrm{~h}$ in vacuum, and then heated at $120^{\circ} \mathrm{C}$ for $2 \mathrm{~h}$. Metallic lithium (Honjo Metal Co., Ltd.) was used as a negative electrode. The electrolyte solution used was $1.0 \mathrm{~mol} \mathrm{dm}{ }^{-3} \mathrm{LiPF}_{6}$ dissolved in ethylene carbonate : dimethyl carbonate ( $3: 7$ by volume, battery grade; Kishida Chemical Corp., Ltd.) or $1.0 \mathrm{~mol} \mathrm{dm}{ }^{-3} \mathrm{NaPF}_{6}$ dissolved in propylene carbonate (battery grade; Kishida Chemical Co., Ltd.). Two-electrode cells (TJ-AC; Tomcell Japan) were assembled in an Ar-filled glovebox. The cells were cycled at a rate of $10 \mathrm{~mA} \mathrm{~g}^{-1}$ at room temperature.

\section{Characterization of metastable $\mathrm{LiMnO}_{2}$ and $\mathrm{NaMnO}_{2}$}

$\mathrm{X}$-ray diffraction (XRD) patterns of the samples were collected using an X-ray diffractometer (D2 PHASER; Bruker Corp., Ltd.) equipped with a one dimensional X-ray detector using $\mathrm{Cu} \mathrm{K} \alpha$ radiation generated at $300 \mathrm{~W}(30 \mathrm{kV}$ and $10 \mathrm{~mA})$ with a Ni filter. An airtight sample holder was used for the XRD measurement.

Synchrotron XRD data were collected on the beamline BL02B2 at SPring-8 synchrotron facility in Japan. The measurement was conducted using an automatic powder diffraction system for Debye-Scherrer geometry by placing the sample in a glass capillary. The wavelength used was $0.5003 \AA$, which was calibrated with $\mathrm{CeO}_{2}$ as a reference sample. The morphological features of the samples were observed using a scanning electron microscope (SEM, JEOM, JCM-6000) with an acceleration voltage of $15 \mathrm{keV}$. Elemental mapping of the samples was also collected using an energy-dispersive X-ray (EDX) spectrometer.

Transmission electron microscopy (TEM) examination was conducted on a JEOL JEM-ARM200F instrument operated under $200 \mathrm{kV}$. The samples were dispersed in dimethyl carbonate and then supported on a copper grid. A bright-field scanning TEM (STEM) image and EDX spectra and maps were acquired in STEM mode. In addition, bright-field images and selected area electron diffraction patterns were collected in the parallel beam mode.

Hard X-ray absorption spectroscopy (XAS) at the Mn K-edge was performed at beamline BL-12C of the Photon Factory Synchrotron Source in Japan. Hard X-ray absorption spectra were collected with a silicon monochromator in transmission mode. The intensity of incident and transmitted X-rays was measured using an ionization chamber at room temperature. Composite electrode samples were prepared using the two- 
electrode cells at a rate of $10 \mathrm{~mA} \mathrm{~g}^{-1}$. The composite electrodes were rinsed with dimethyl carbonate and sealed in a waterresistant polymer film in the Ar-filled glovebox.

\section{Results and discussion}

Fig. 1 shows the X-ray diffraction (XRD) patterns of $\mathrm{LiMnO}_{2}$ and $\mathrm{NaMnO}_{2}$ before and after mechanical milling. Structural analysis was carried out using RIETAN-FP, ${ }^{26}$ and the schematic of crystal structures were drawn using the VESTA program. ${ }^{27}$ The $\mathrm{XRD}$ pattern of the as-prepared sample of $\mathrm{LiMnO}_{2}$ is assigned as the zigzag-type layered structure with high crystallinity. After mechanical milling, all diffraction lines of the zigzag-type structure disappear and instead, a cation-disordered rocksalt phase with broad diffraction lines is obtained (see also ESI Fig. S1 $\dagger$ ). A fitting result by Rietveld analysis is also shown in ESI Fig. S2. $\dagger$ Although the major phase is successfully assigned to the cation-disordered rocksalt-type structure, an asymmetric peak profile suggests inhomogeneity of the Li/Mn distribution and presence of defects/strains in the structure. The particle sizes of the samples are significantly reduced by mechanical milling. Large particles with the size of $>10 \mu \mathrm{m}$ are effectively reduced to submicron-meter size, but agglomerated particles $(\sim 2 \mu \mathrm{m})$ are also found. Similarly to $\mathrm{LiMnO}_{2}$, highly crystalline $\mathrm{NaMnO}_{2}$ with an $\alpha-\mathrm{NaFeO}_{2}$-type layered structure is changed into the disordered phase. However, in contrast to $\mathrm{LiMnO}_{2}$, it is noted that high uniformity in particle morphology is found by SEM for $\mathrm{NaMnO}_{2}$ after mechanical milling. The average particle size is slightly increased by mechanical milling because of agglomeration of the nanosize primary particles. Moreover, the lattice parameter $(a=4.414 \AA)$ for $\mathrm{NaMnO}_{2}$ after mechanical milling is clearly larger than that of the Li counterpart $(a=$ $4.167 \AA)$, and this result is consistent with the fact that $\mathrm{Na}^{+}(1.16$ $\AA)$ is much larger than $\mathrm{Li}^{+}(0.90 \AA) .{ }^{28}$ Notably, a small peak at $18^{\circ}$ observed for rocksalt $\mathrm{NaMnO}_{2}$ originates from a non-reacted layered phase. Additionally, the peak area of the 111 diffraction line is clearly larger for rocksalt $\mathrm{NaMnO}_{2}$ because the intensity of this diffraction line depends on the difference in

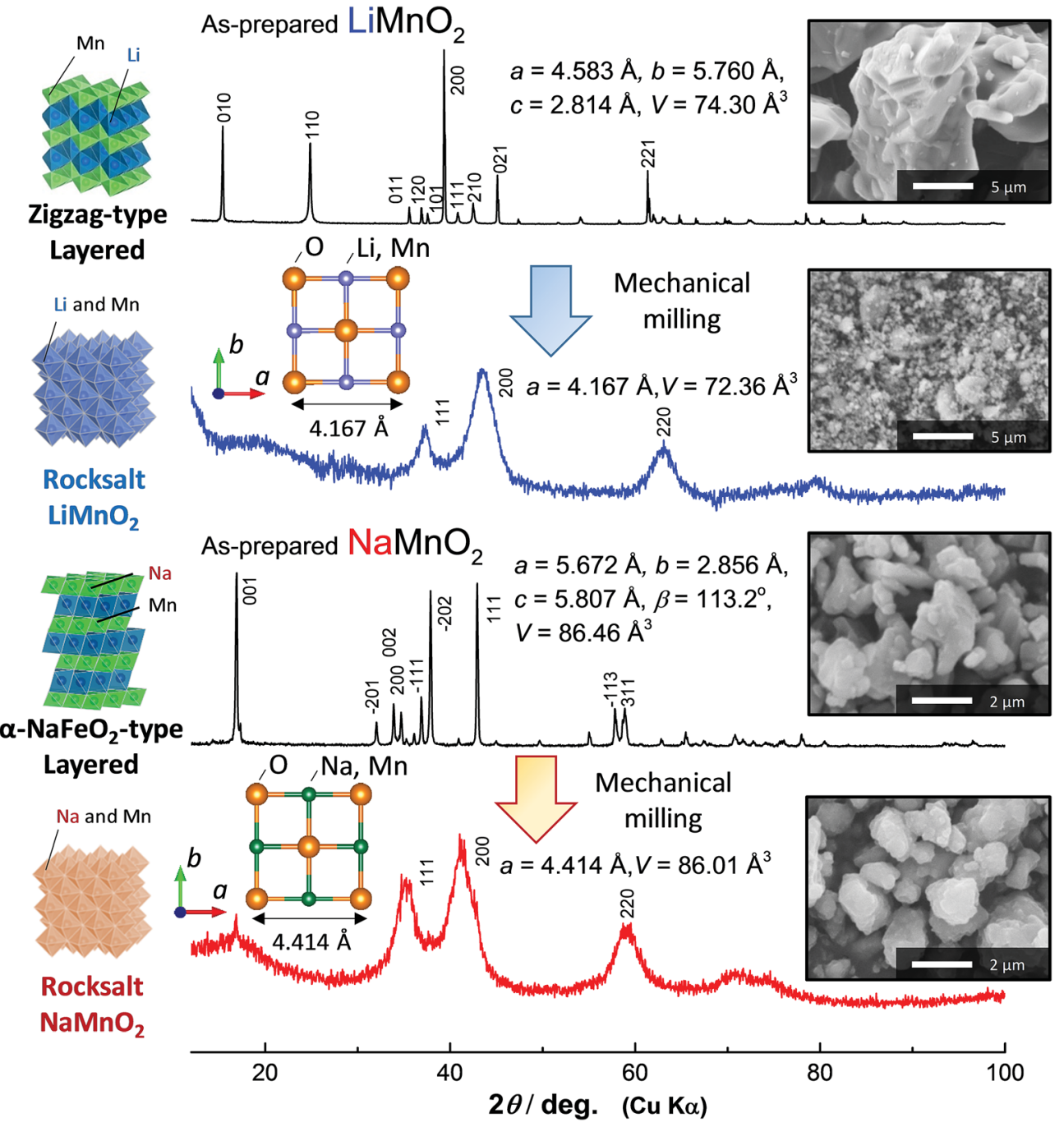

Fig. 1 Synthesis of cation-disordered rocksalt-type $\mathrm{LiMnO}_{2}$ and $\mathrm{NaMnO}_{2}$ by mechanical milling. Schematic illustrations of crystal structures, Xray diffraction patterns, and particle morphology are compared. 
scattering factors between cationic (4a) and anionic (4b) sites, and destructive interference occurs. Therefore, Na incorporation results in a large difference in atomic scattering factors for the $4 \mathrm{a}$ and $4 \mathrm{~b}$ sites, leading to increase in the area of 111 diffraction line.

The particle morphology and nanostructures of the samples were further analyzed by a transmission electron microscope (Fig. 2). For $\mathrm{LiMnO}_{2}$ after milling, the sample consists of nanosize particles with sizes of 3-5 $\mathrm{nm}$, forming agglomerated particles. Similar nanostructures are found for $\mathrm{NaMnO}_{2}$ after milling. The formation of nanosize particles is further verified by Debye-Scherrer rings that are observed by electron diffraction from single particles. Lattice fringes were observed from high-resolution TEM images, suggesting that the particles contain highly crystalline nanosize domains. Notably, the surface area of the samples prepared by mechanical milling is relatively small because these particles are tightly agglomerated, which also leads to the formation of enriched domain boundaries in individual particles. ${ }^{29}$ Local structural differences in the samples were further examined by Raman spectroscopy, as shown in Fig. 3. The profile of the Raman spectrum for the asprepared $\mathrm{LiMnO}_{2}$ is consistent with the data reported in the literature ${ }^{30}$ and the spectrum changes into a different profile after milling. Similarly, the feature of the Raman spectra of the as-prepared $\mathrm{NaMnO}_{2}$ is similar to a sodium-containing layered material, $\mathrm{NaCoO}_{2} \cdot{ }^{31}$ Both rocksalt samples have a similar
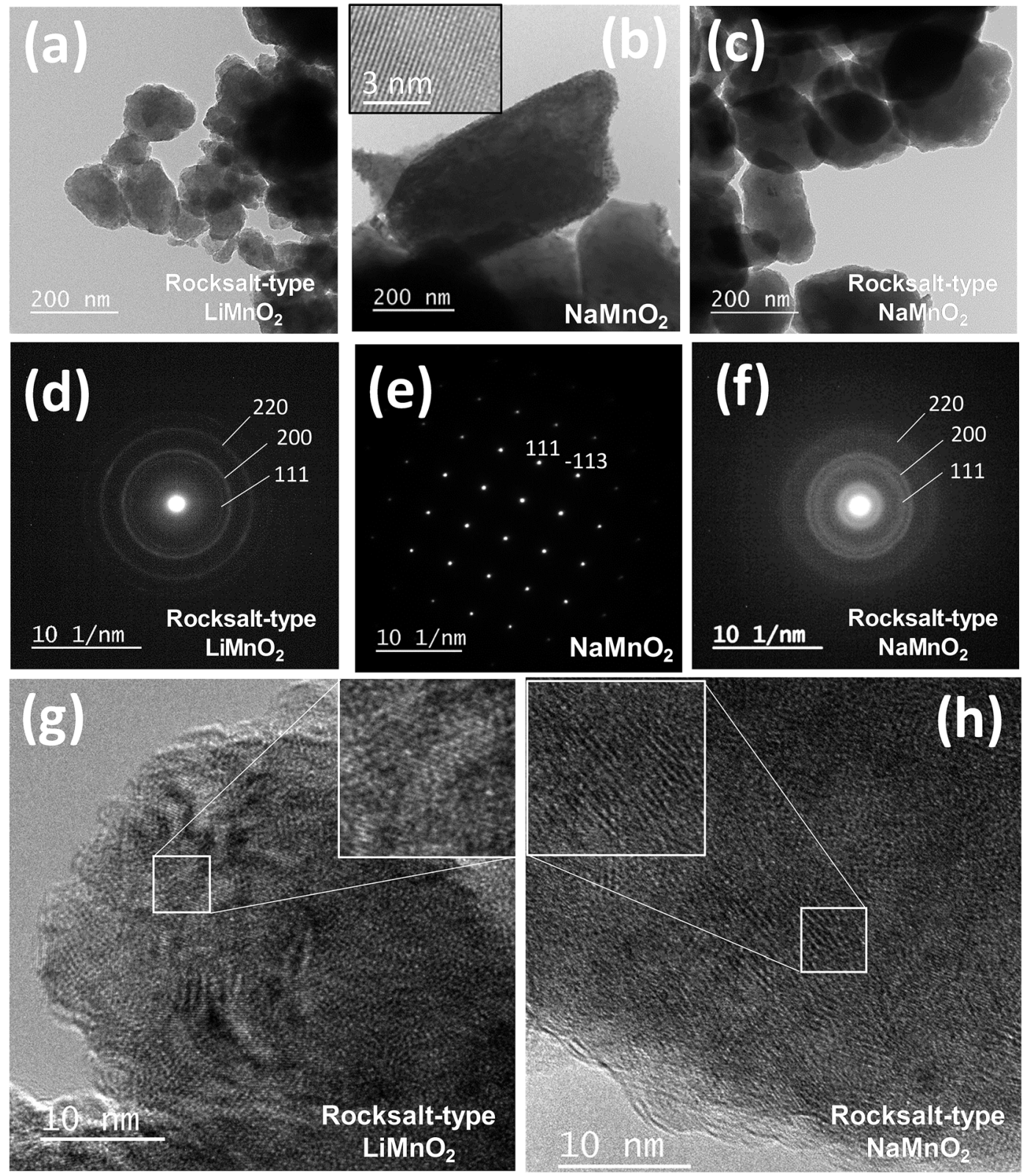

Fig. 2 Nanostructures of cation-disordered rocksalt-type $\mathrm{LiMnO}_{2}$ and $\mathrm{NaMnO}_{2}$ : (a-c) TEM images of the samples; (d-f) electron diffraction (ED) patterns of the samples; and ( $g$ and $h$ ) high-resolution TEM images of the samples. High-resolution TEM image of (b) is also shown in the inset. The ED pattern of (e) is indexed to the [1-21] zone axis. 

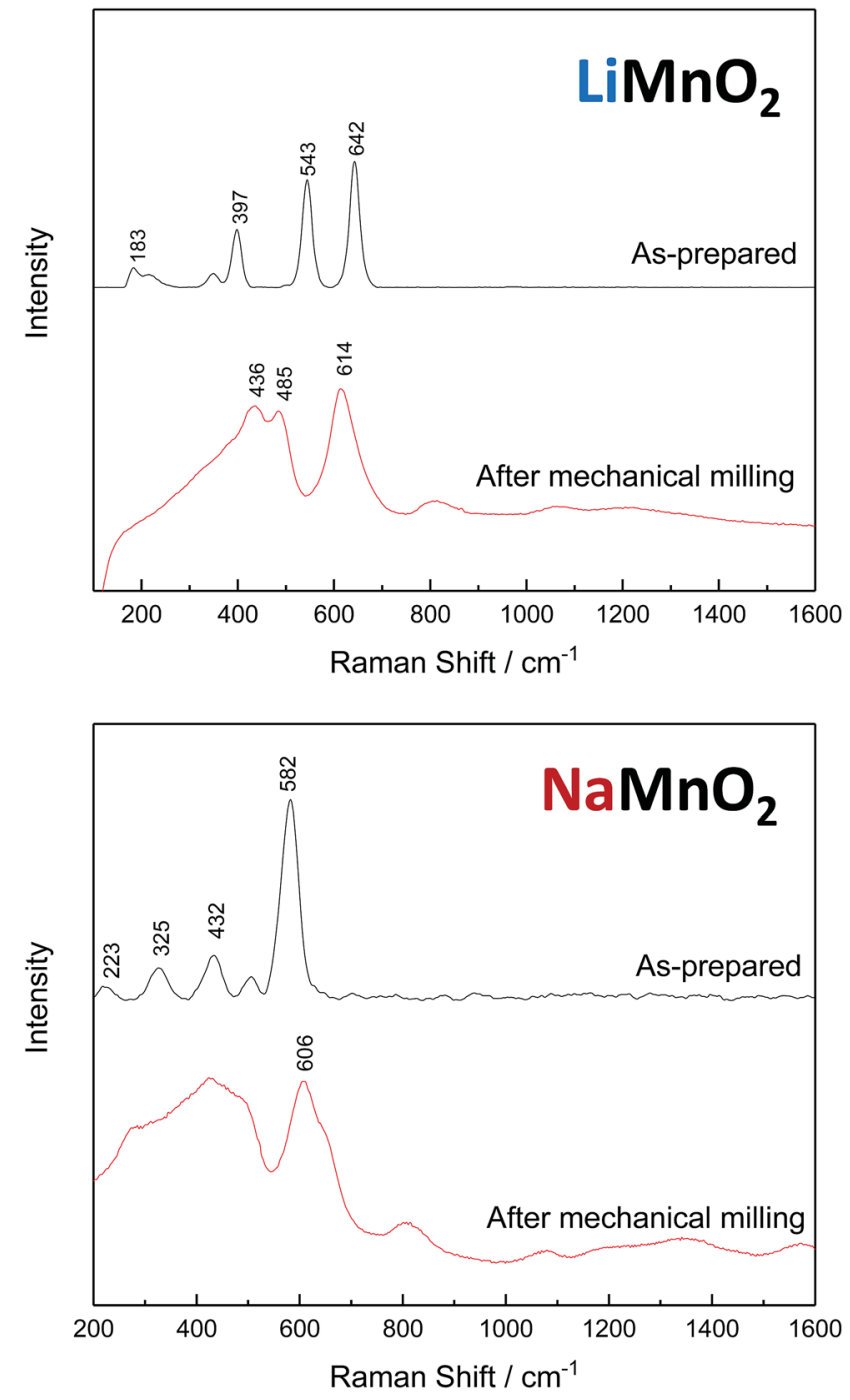

Fig. 3 Raman spectra for $\mathrm{LiMnO}_{2}$ and $\mathrm{NaMnO}_{2}$ before and after milling.

spectroscopic feature, which is consistent with the similarity of the crystal structure. Moreover, the Raman spectra of both phases resemble the spectrum of $\mathrm{MnO}$ with rocksalt structure, which is characterized by the presence of two broad bands at 531 and $654 \mathrm{~cm}^{-1} .^{32}$ The peak at $531 \mathrm{~cm}^{-1}$ originates from the $\mathrm{Mn}-\mathrm{O}$ stretching mode in cubic oxygen lattice. ${ }^{32}$ The energy of bands for $\mathrm{LiMnO}_{2}$ and $\mathrm{NaMnO}_{2}$ is slightly different from $\mathrm{MnO}$ because vibration energy changes as a function of $\mathrm{Mn}-\mathrm{O}$ distances.

The Li storage properties of the samples with the cationdisordered rocksalt structures were further studied by galvanostatic charge/discharge method (Fig. 4). The reversible capacity of zigzag layered $\mathrm{LiMnO}_{2}$ is limited to $70 \mathrm{~mA} \mathrm{~h} \mathrm{~g}^{-1}$ in the initial cycle and gradually increases to $150 \mathrm{~mA} \mathrm{~h} \mathrm{~g}^{-1}$. The $10^{\text {th }}$ charge/discharge curves are shown in ESI Fig. S3. $\uparrow$ Two voltage plateaus at 3 and $4 \mathrm{~V}$ regions appear after cycling, which is a characteristic feature of spinel phase formation. ${ }^{33} \mathrm{LiMnO}_{2}$ transitions into a spinel phase with low crystallinity within initial few cycles. ${ }^{34}$ In contrast, phase transition is partially

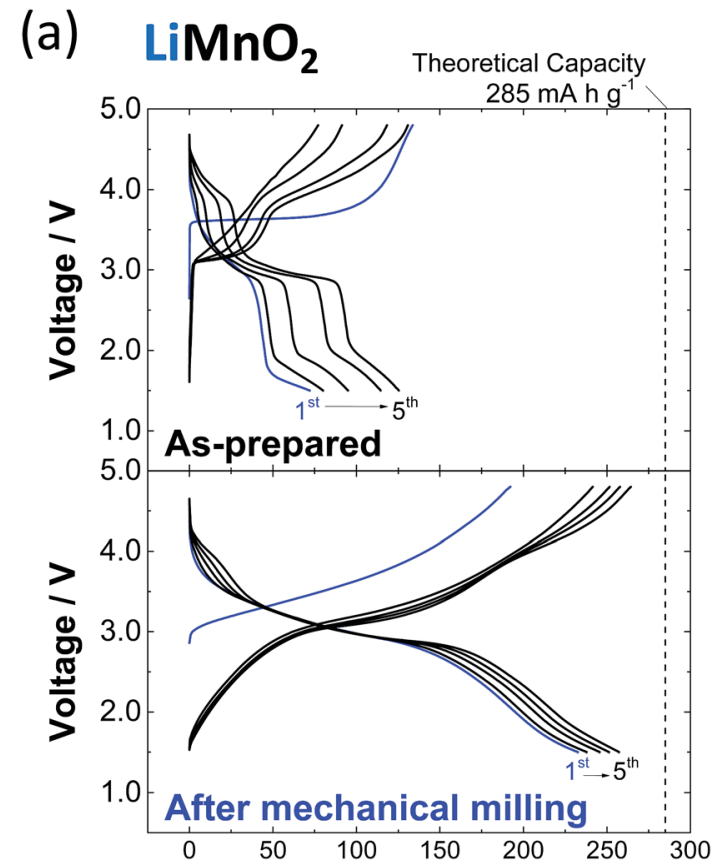

(b) Capacity / $\mathrm{mA} \mathrm{h} \mathrm{g}^{-1}$

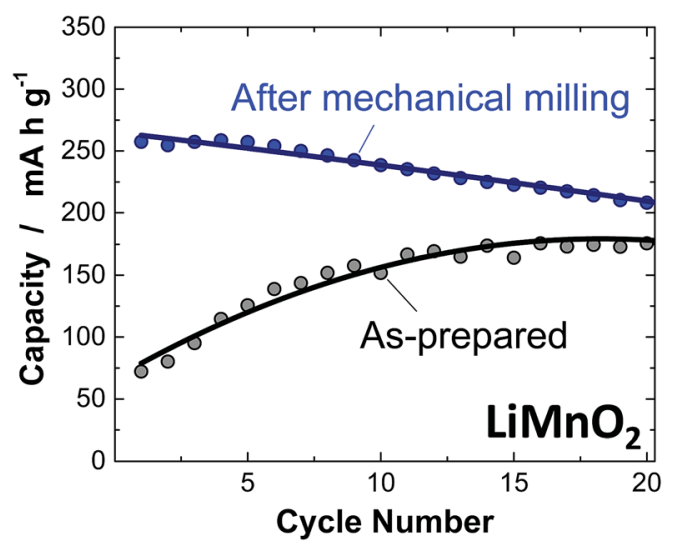

Fig. 4 Comparison of electrochemical properties of zigzag-type and cation-disordered rocksalt-type $\mathrm{LiMnO}_{2}$ : (a) galvanostatic charge/ discharge curves and (b) capacity retention in a Li cell.

suppressed for the rocksalt phase. The sample delivers $c a$. $250 \mathrm{~mA} \mathrm{~h} \mathrm{~g}{ }^{-1}$ of a discharge capacity at the initial cycle. It is noted that Obrovac et al. reported the synthesis of $\mathrm{LiMnO}_{2}$ with a disordered rocksalt structure. ${ }^{35}$ They have successfully prepared the rocksalt phase from the mixture of $\mathrm{Li}_{2} \mathrm{O}, \mathrm{MnO}_{2}$, and $\mathrm{Mn}$ metal by mechanical milling. However, the observed reversible capacity is limited to $120 \mathrm{~mA} \mathrm{~h} \mathrm{~g}^{-1}$, which is much smaller than the results shown in Fig. 4a. This difference probably originates from difference in the nanostructures of the samples because mechanical energy, including frictional and impact forces, is efficiently applied to the samples by planetary mechanical milling used in this study. It should be noted that the TEM/SEM images shown in Fig. 2 were collected before mixing with acetylene black (AB), and the electrochemical properties shown in Fig. 4 were obtained from the carbon 
composite sample. Electrochemical data of the as-prepared rocksalt sample is also shown in ESI Fig. S4. $\dagger$ Although the cyclability of the as-prepared electrode materials is improved by mixing with $\mathrm{AB}$, a large initial discharge capacity of $225 \mathrm{~mA} \mathrm{~h} \mathrm{~g}^{-1}$ is observed for the as-prepared rocksalt sample. SEM/EDX images of the rocksalt sample before/after the mixing with $\mathrm{AB}$ are also shown in ESI Fig. S5. $\dagger$ No clear difference in particle morphology is found before/after mixing with $\mathrm{AB}$.

Changes in the crystal structure were examined by synchrotron X-ray diffraction, as shown in ESI Fig. S6. $\uparrow$ SXRD data were collected at the beamline BL02B2 at SPring-8 synchrotron facility in Japan. ${ }^{36}$ The rocksalt phase $(a=4.173 \AA)$ with low crystallinity shrinks after charging $(a=4.072 \AA)$, and shifts back to the original position ( $a=4.172 \AA$ ) after reduction to $1.5 \mathrm{~V}$. The volume change is calculated to be $c a .8 \%$, which is much smaller than that of the spinel phase $\left(13 \%\right.$ from cubic $\lambda-\mathrm{MnO}_{2}$ to tetragonal $\mathrm{Li}_{2} \mathrm{Mn}_{2} \mathrm{O}_{4}$ ). The initial charge capacity is smaller than the initial discharge capacity, indicating that rocksalt $\mathrm{Li}_{x} \mathrm{MnO}_{2}$ is a lithium deficient phase. Such a trend, observed due to the formation of the lithium deficient phase, is generally observed for samples prepared by mechanical milling. ${ }^{\mathbf{2 2 , 2 4 , 2 5}} \mathrm{A}$ small voltage plateau at $4 \mathrm{~V}$ gradually appears in the following cycles, indicating that spinel domains are gradually formed in the sample. However, the formation of the spinel phase is not clearly observed by XRD, and the original rocksalt phase is still found to be the major phase after 5 cycles (ESI Fig. S7 $\dagger$ ). Moreover, such a phase evolution is terminated after several cycles, and no further progress is found after 10 cycles from the electrochemical data (Fig. 5). The growth of the voltage plateau observed at $4 \mathrm{~V}$, as observed for zigzag-layered $\mathrm{LiMnO}_{2}$, is effectively suppressed for the rocksalt metastable phase. These findings suggest that the energy of nucleation and growth of the spinel phase on electrochemical cycling for metastable $\mathrm{LiMnO}_{2}$ is increased compared with those observed for zigzag layered $\mathrm{LiMnO}_{2}$ as the thermodynamically stable phase.

The electrochemical properties of rocksalt $\mathrm{NaMnO}_{2}$ are shown in Fig. 6. Similar to rocksalt $\mathrm{LiMnO}_{2}$, the sample delivers a large reversible capacity of $200 \mathrm{~mA} \mathrm{~h} \mathrm{~g}^{-1}$ in a Na cell. Similar initial discharge capacity is observed for as-prepared $\mathrm{NaMnO}_{2}$, but much better capacity retention is realized for rocksalt $\mathrm{NaMnO}_{2}$. From the initial charge/discharge capacity, it is expected that some amount of cationic defects are created by mechanical milling as compared with rocksalt $\mathrm{LiMnO}_{2}$ synthesized by the same method. Similar phenomena have been also observed for samples prepared by mechanical milling. ${ }^{23,24}$ From the difference in initial and second charge capacities, approximately $15 \%$ of Li defects in the structure are expected. Chemical composition analysis by EDX reveals that the molar ratio of $\mathrm{Na}: \mathrm{Mn}$ is close to $1: 1$, suggesting that $\mathrm{Na}$ ions partially exist as $\mathrm{Na}_{2} \mathrm{CO}_{3}$ and/or $\mathrm{NaOH}$. A similar phenomenon is expected for rocksalt $\mathrm{LiMnO}_{2}$. In addition, for the case of rocksalt $\mathrm{NaCrO}_{2}$, clear deterioration of electrode performance is observed, probably because of the active particle surface created by mechanical milling. ${ }^{29}$ In contrast, for $\mathrm{NaMnO}_{2}$, the observed reversible capacity observed $>80 \%$ of the theoretical capacity, and relatively small polarization for charge/discharge processes is observed. Structural change on electrochemical cycling was further examined by XRD (ESI Fig. S8 $\dagger$ ), and $c a$. 20\% of volume change was noted. The crystallinity of the sample also reduced after charging, but recovers back after discharge. Although large strain is expected according to the XRD data, good capacity retention is evidenced for the metastable phase, as shown in Fig. 6. Further study is needed to understand difference in electrochemical behavior of rocksalt $\mathrm{NaCrO}_{2}$ and $\mathrm{NaMnO}_{2}$ prepared by mechanical milling.

The charge compensation mechanisms of rocksalt $\mathrm{LiMnO}_{2}$ and $\mathrm{NaMnO}_{2}$ were further examined by X-ray absorption

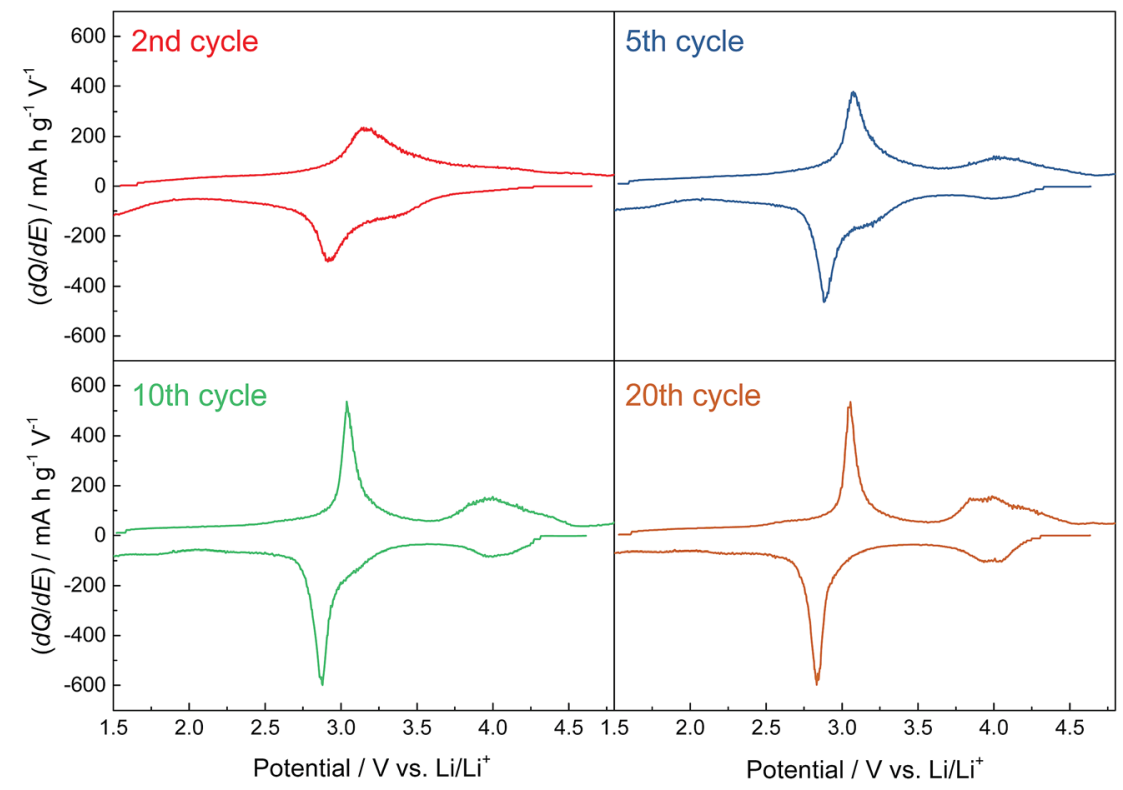

Fig. 5 Changes in differential capacity plots of $\mathrm{Li}_{x} \mathrm{MnO}_{2}$ upon electrochemical cycles. 

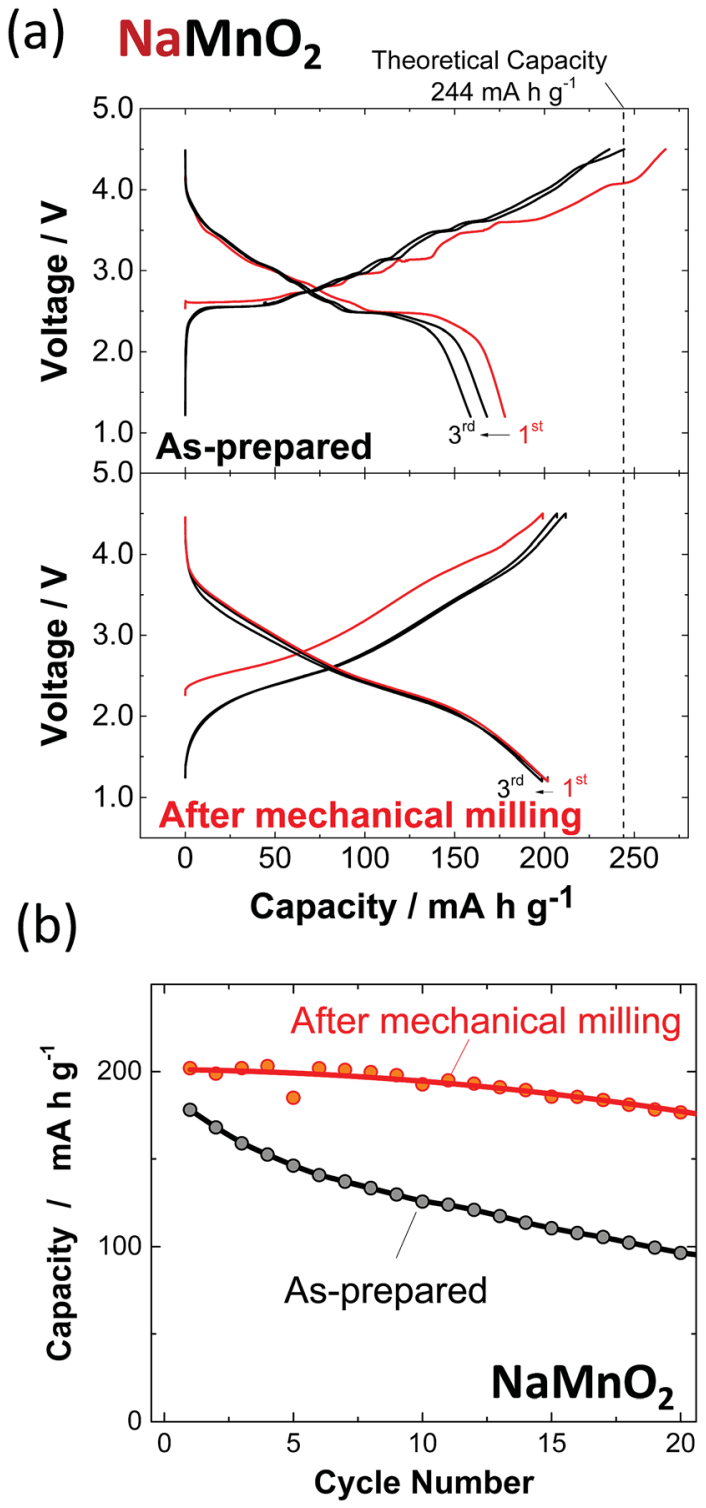

Fig. 6 Comparison of electrochemical properties of layered and cation-disordered rocksalt-type $\mathrm{NaMnO}_{2}$ : (a) galvanostatic charge/ discharge curves and (b) capacity retention in a Na cell.

spectroscopy (XAS), as shown in Fig. 7. A slight difference in profiles for the XAS spectra is noted for $\mathrm{LiMnO}_{2}$ and $\mathrm{NaMnO}_{2}$. The larger ionic radius for $\mathrm{Na}^{+}$, as shown in Fig. 1, changes the local structure of both samples, and the difference in local structures influences the profile of XAS spectra. ${ }^{37}$ After electrochemical delithiation/desodiation, XAS spectra of both phases shifted to a higher energy region (peak top shift; $c a .3 \mathrm{eV}$ for $\mathrm{Li}$ and $2 \mathrm{eV}$ for $\mathrm{Na}$ ), indicating the oxidation of $\mathrm{Mn}$ to the tetravalent state. ${ }^{38}$ This process is highly reversible, and the XAS spectra shift back to their original positions. However, for rocksalt $\mathrm{LiMnO}_{2}$, after discharging to $1.5 \mathrm{~V}$, an additional peak shift to the lower energy region is observed compared with the as-prepared rocksalt $\mathrm{NaMnO}_{2}$. This observation is consistent with the defect formation associated with the partial oxidation of Mn by mechanical milling. Pre-edge peaks for fully charged/
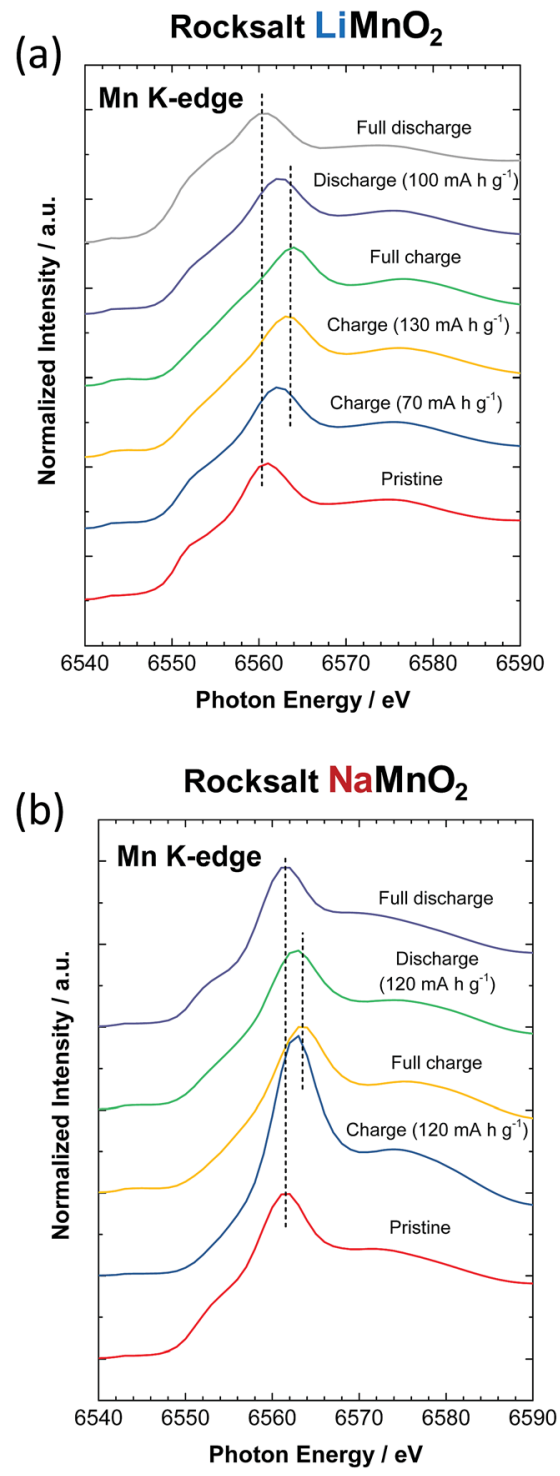

Fig. 7 Charge compensation mechanisms of cation-disordered rocksalt-type $\mathrm{Li}_{x} \mathrm{MnO}_{2}$ and $\mathrm{Na}_{x} \mathrm{MnO}_{2}$ with different charge/discharge conditions examined by X-ray absorption spectroscopy. For $\mathrm{Li}_{x} \mathrm{MnO}_{2}$. XAS spectra of full charged/discharged states are compared with those of reference materials in ESI Fig. S9. $\dagger$

discharged $\mathrm{Li}_{x} \mathrm{MnO}_{2}$ are also highlighted in ESI Fig. S9. $\dagger$ Approximately $2 \mathrm{eV}$ shift in the pre-edge peak is consistent with the data observed in main edges as mentioned above. In addition, changes in the pre-edge profiles possibly suggest changes in the local environment for Mn ions. ${ }^{38}$

Although the accessible Li content by percolative migration is expected to be low for the "stoichiometric" cation-disordered system, the experimental data shows that electrode performance of both nanosize $\mathrm{LiMnO}_{2}$ and $\mathrm{NaMnO}_{2}$ with the disordered structure is much better than the electrode performance of those with the layered system. The percolative probability is inevitably reduced for the stoichiometric phase, but good electrochemical properties are realized by shortening Li/Na migration length in particles, as shown in this study. In addition, as 
mentioned above, the surface area of the nanosize oxides prepared by mechanical milling is relatively low (less than $10 \mathrm{~m}^{2}$ $\left.\mathrm{g}^{-1}\right),{ }^{29}$ indicating that nanosize particles contain many grain boundaries. The unique nanostructure, enriched grain boundaries in each individual particle, possibly assists Li/Na migration, leading to better electrode performance for the "stoichiometric" disordered phase. Nevertheless, the kinetics is hindered when the stoichiometric rocksalt phase is used as the electrode material. The discharge capacity of rocksalt $\mathrm{NaMnO}_{2}$ is reduced to $120 \mathrm{~mA} \mathrm{~h} \mathrm{~g}^{-1}$ at a rate of $400 \mathrm{~mA} \mathrm{~g}^{-1}$, as shown ESI Fig. S10. $\dagger$ Further theoretical understanding to explain our experimental observation, including the possibility of $\mathrm{Li} / \mathrm{Na}$ migration at grain boundary, is therefore encouraged.

\section{Conclusions}

Rocksalt $\mathrm{LiMnO}_{2}$ and $\mathrm{NaMnO}_{2}$ as metastable phases were successfully prepared by mechanical milling, and the electrochemical properties of these phases are examined. Although these thermodynamically stable phases of $\mathrm{LiMnO}_{2}$ and $\mathrm{NaMnO}_{2}$ have been extensively studied for battery applications, significant improvement was realized by the use of metastable phases with the unique nanostructures. Our research progress on nanostructured metastable phases for battery applications potentially realizes the further development of rechargeable $\mathrm{Li}$ / $\mathrm{Na}$ batteries with high energy density in the future.

\section{Conflicts of interest}

There are no conflicts to declare.

\section{Acknowledgements}

The author acknowledges research funding from JSPS KAKENHI Grant Number $18 \mathrm{H} 02076$ and MEXT program "Elements Strategy Initiative to Form Core Research Center", MEXT; Ministry of Education Culture, Sports, Science and Technology, Japan. The synchrotron X-ray absorption work was done under the approval of the Photon Factory Program Advisory Committee (Proposal No. 2017G005). The synchrotron radiation experiments were performed at the BL02B2 of SPring8 with the approval of the Japan Synchrotron Radiation Research Institute (JASRI) (Proposal 2017B1218).

\section{References}

1 B. Dunn, H. Kamath and J.-M. Tarascon, Science, 2011, 334, 928-935.

2 N. Yabuuchi and S. Komaba, Sci. Technol. Adv. Mater., 2014, 15, 043501.

3 T. Ohzuku, M. Kitagawa and T. Hirai, J. Electrochem. Soc., 1990, 137, 769-775.

4 M. M. Thackeray, P. J. Johnson, L. A. Depicciotto, P. G. Bruce and J. B. Goodenough, Mater. Res. Bull., 1984, 19, 179-187.

5 J. M. Tarascon, E. Wang, F. K. Shokoohi, W. R. McKinnon and S. Colson, J. Electrochem. Soc., 1991, 138, 2859-2864.

6 Y. Xia and M. Yoshio, J. Electrochem. Soc., 1996, 143, 825-833.
7 J. N. Reimers, E. W. Fuller, E. Rossen and J. R. Dahn, J. Electrochem. Soc., 1993, 140, 3396-3401.

8 T. Ohzuku, S. Kitano, M. Iwanaga, H. Matsuno and A. Ueda, J. Power Sources, 1997, 68, 646-651.

9 H. Wang, Y. I. Jang and Y. M. Chiang, Electrochem. Solid-State Lett., 1999, 2, 490-493.

10 X. H. Ma, H. L. Chen and G. Ceder, J. Electrochem. Soc., 2011, 158, A1307-A1312.

11 F. Capitaine, P. Gravereau and C. Delmas, Solid State Ionics, 1996, 89, 197-202.

12 A. R. Armstrong and P. G. Bruce, Nature, 1996, 381, 499-500.

13 M. Tabuchi, K. Ado, H. Kobayashi, H. Kageyama, C. Masquelier, A. Kondo and R. Kanno, J. Electrochem. Soc., 1998, 145, L49-L52.

14 Y. I. Jang, B. Huang, Y. M. Chiang and D. R. Sadoway, Electrochem. Solid-State Lett., 1998, 1, 13-16.

15 J. Lee, D.-H. Seo, M. Balasubramanian, N. Twu, X. Li and G. Ceder, Energy Environ. Sci., 2015, 8, 3255-3265.

16 N. Yabuuchi, M. Nakayama, M. Takeuchi, S. Komaba, Y. Hashimoto, T. Mukai, H. Shiiba, K. Sato, Y. Kobayashi, A. Nakao, M. Yonemura, K. Yamanaka, K. Mitsuhara and T. Ohta, Nat. Commun., 2016, 7, 13814.

17 M. Nakajima and N. Yabuuchi, Chem. Mater., 2017, 29, 69276935.

18 R. Wang, X. Li, L. Liu, J. Lee, D.-H. Seo, S.-H. Bo, A. Urban and G. Ceder, Electrochem. Commun., 2015, 60, 70-73.

19 J. Lee, A. Urban, X. Li, D. Su, G. Hautier and G. Ceder, Science, 2014, 343, 519-522.

20 A. Urban, J. Lee and G. Ceder, Adv. Energy Mater., 2014, 4, 1400478.

21 A. Kitajou, E. Kobayashi and S. Okada, Electrochemistry, 2015, 83, 885-888.

22 R. Y. Chen, S. H. Ren, M. Knapp, D. Wang, R. Witter, M. Fichtner and H. Hahn, Adv. Energy Mater., 2015, 5, 1401814.

23 S. Hoshino, A. M. Glushenkov, S. Ichikawa, T. Ozaki, T. Inamasu and N. Yabuuchi, ACS Energy Lett., 2017, 2, 733-738.

24 N. Takeda, S. Hoshino, L. Xie, S. Chen, I. Ikeuchi, R. Natsui, K. Nakura and N. Yabuuchi, J. Power Sources, 2017, 367, 122129.

25 R. A. House, L. Jin, U. Maitra, K. Tsuruta, J. W. Somerville, D. P. Forstermann, F. Massel, L. Duda, M. R. Roberts and P. G. Bruce, Energy Environ. Sci., 2018, 11, 926-932.

26 F. Izumi and K. Momma, Solid State Phenom., 2007, 130, 1520.

27 K. Momma and F. Izumi, J. Appl. Crystallogr., 2011, 44, 12721276.

28 R. D. Shannon, Acta Crystallogr., Sect. A: Cryst. Phys., Diffr., Theor. Gen. Crystallogr., 1976, 32, 751-767.

29 Y. Tsuchiya, A. M. Glushenkov and N. Yabuuchi, ACS Appl. Nano Mater., 2018, 1, 364-370.

30 L. Z. Zhao, Y. W. Chen and G. R. Wang, Solid State Ionics, 2010, 181, 1399-1402.

31 Y. G. Shi, Y. L. Liu, H. X. Yang, C. J. Nie, R. Jin and J. Q. Li, Phys. Rev. B: Condens. Matter Mater. Phys., 2004, 70, 052502. 
32 C. M. Julien, M. Massot and C. Poinsignon, Spectrochim. Acta, Part A, 2004, 60, 689-700.

33 Y. I. Jang, B. Huang, H. Wang, D. R. Sadoway and Y. M. Chiang, J. Electrochem. Soc., 1999, 146, 3217-3223.

34 X. Y. Tu and K. Y. Shu, J. Solid State Electrochem., 2008, 12, 245-249.

35 M. N. Obrovac, O. Mao and J. R. Dahn, Solid State Ionics, 1998, 112, 9-19.
36 S. Kawaguchi, M. Takemoto, K. Osaka, E. Nishibori, C. Moriyoshi, Y. Kubota, Y. Kuroiwa and K. Sugimoto, Rev. Sci. Instrum., 2017, 88, 085111.

37 K. Kubobuchi, M. Mogi, M. Matsumoto, T. Baba, C. Yogi, C. Sato, T. Yamamoto, T. Mizoguchi and H. Imai, J. Appl. Phys., 2016, 120, 142125.

38 F. Farges, Phys. Rev. B: Condens. Matter Mater. Phys., 2005, 71, 155109. 